
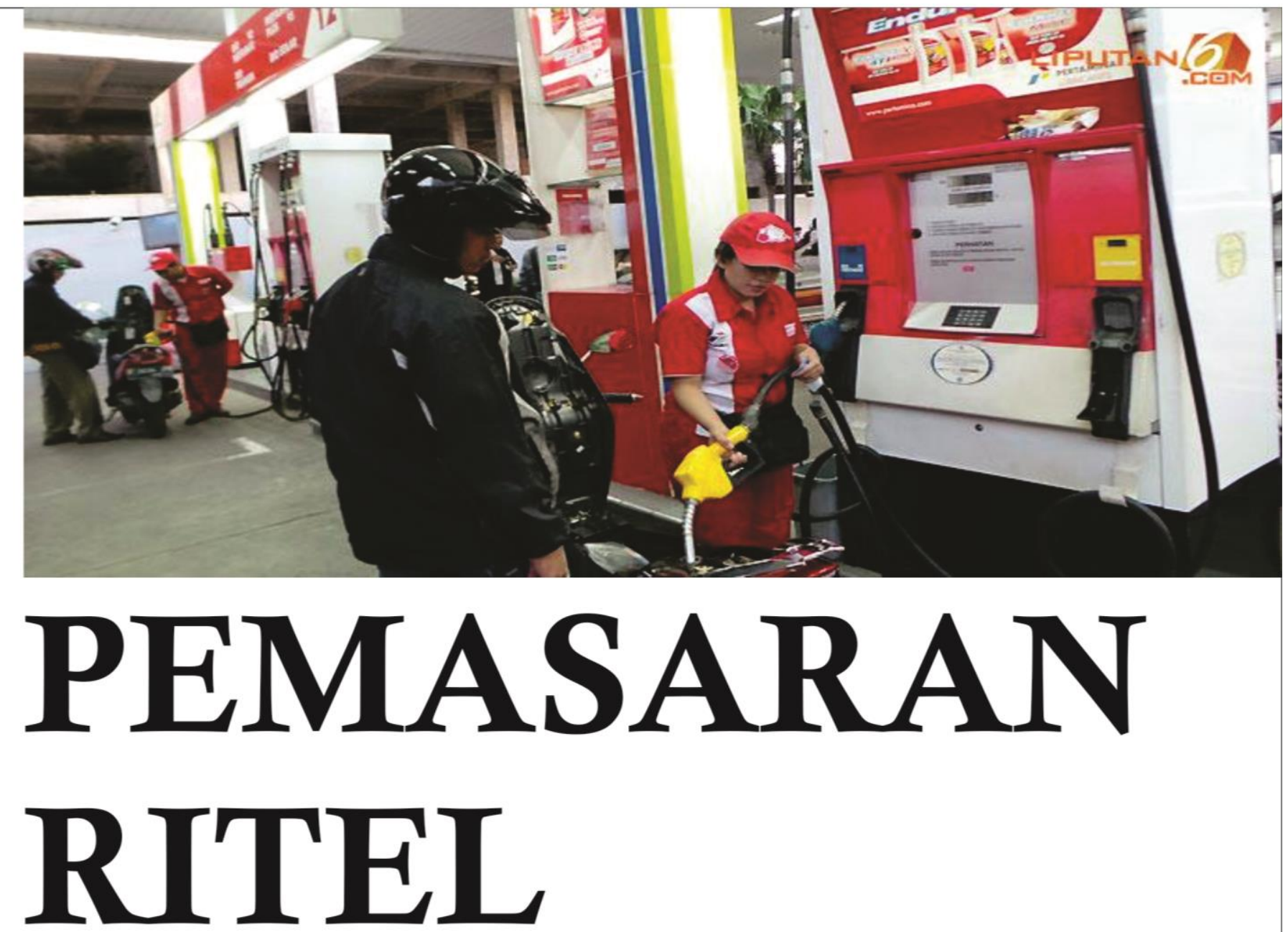

KESATUAN
PRESS

KESATUAN

entrepreneur center
ADIL FADILLAH BAMBANG HENGKY R. WEMAN SUARDY 


\section{PEMASARAN}

RITEL

\section{Adil Fadillah Bambang Hengky Weman Suardy}




\section{Perilaku Pembelian Pelanggan Ritel}

\section{TUJUAN INSTRUKSIONAL}

Setelah Mempelajari Bab ini diharapkan Mahasiswa mampu mengetahui :

Proses Keputusan Pembelian

- Tipe Keputusan Pembelian

Faktor Yang Mempengaruhi Keputusan Pembelian 


\section{PROSES KEPUTUSAN PEMBELIAN}

Siapakah konsumen itu?

Konsumen adalah individu, rumah tangga atau suatu organisasi yang terlibat secara langsung atau tidak langsung dalam mencari, mengevaluasi, memutuskan, membeli, menggunakan dan menghabiskan suatu produk berupa barang atau jasa yang mereka harapkan akan memuaskan kebutuhan mereka.

Proses Pembelian dimulai ketika konsumen mengenali adanya kebutuhan yang belum terpenuhi. Kemudian mereka mulai mencari informasi tentang cara memenuhi kebutuhan tersebut: Produk apa yang akan memberi manfaat dan bagaimana cara memperolehnya...

Lalu konsumen mengevaluasi berbagai alternatif produk melalui ritel, katalog dan internet. Dan memilih salah satu di antaranya

Setelah mengevaluasi, konsumen membuat keputusan pembelian pada suatu ritel atau ritel yang lain yang cocok.

Pada suatu kondisi, konsumen akan sangat mempertimbangkan ritel dan produk yang akan dibeli. Hal ini akan membutuhkan waktu.

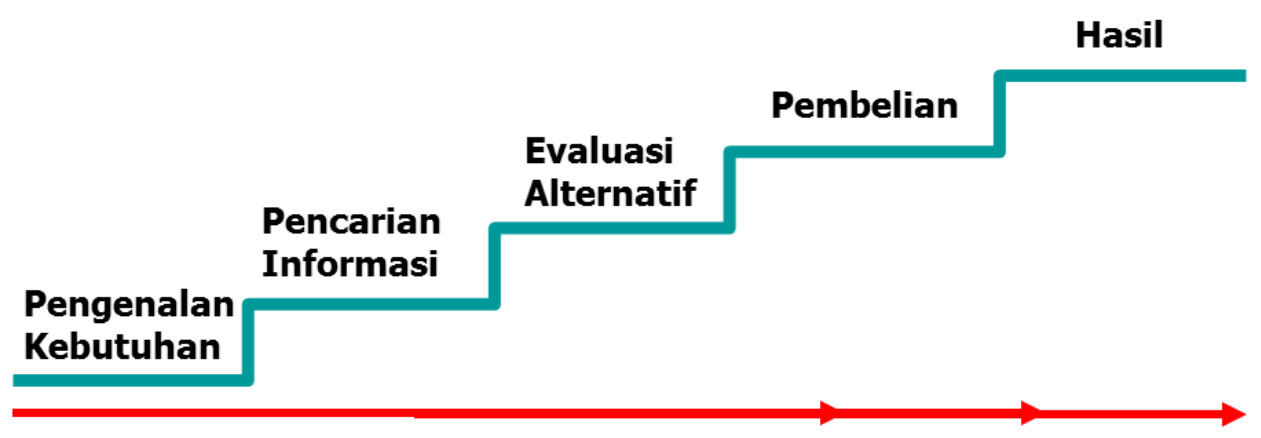

Gambar 3. Proses Keputusan Pembelian 


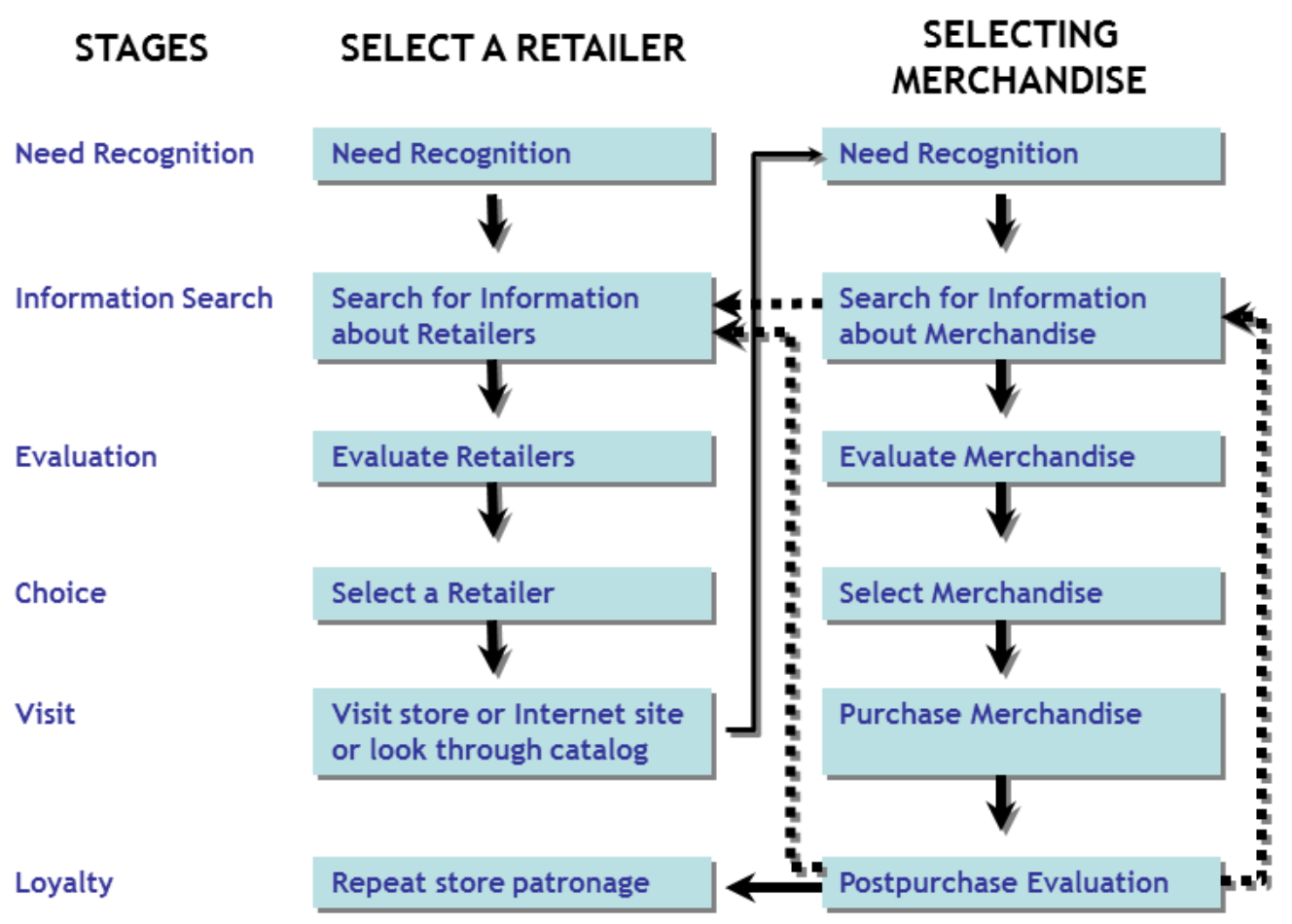

Gambar 4. Proses Pembelian Konsumen Pada Ritel

\section{TIPE KEPUTUSAN PEMBELIAN}

Tiga Proses pengambilan Keputusan Pembelian yang dilakukan konsumen :

EXTENDED PROBLEM SOLVING

Yaitu proses pengambilan keputusan pembelian dimana konsumen mencurahkan waktu dan usaha yang banyak untuk mempertimbangkan suatu pembelian. 
Mereka melakukan hal ini di saat akan membeli produk untuk memenuhi kebutuhan sangat penting atau ketika konsumen hanya mempunyai sedikit pengetahuan tentang produk.

Untuk mengurangi resiko, konsumen akan banyak bertanya ke pihak yang mengetahui tentang produk tersebut. Mereka akan mengunjungi beberapa ritel sampai keputusan tersebut dibuat.

\section{LIMITED PROBLEM SOLVING}

Yaitu proses pengambilan keputusan pembelian dimana konsumen mencurahkan waktu dan usaha yang secukupnya untuk mempertimbangkan suatu pembelian.

Konsumen melakukan hal ini di saat akan membeli produk yang sebelumnya pernah dibeli. Konsumen lebih mempercayai pengalaman dan pengetahuan pribadi dibanding informasi dari pihak lain.

Konsumen cenderung akan membeli produk yang pernah dibelinya dan pada tempat yang pernah dikunjunginya

\section{LIMITED PROBLEM SOLVING}

Yaitu proses pengambilan keputusan pembelian dimana konsumen mencurahkan waktu dan usaha yang sedikit saja untuk mempertimbangkan suatu pembelian.

Di saat konsumen membutuhkan sesuatu maka dengan segera mereka akan memutuskan suatu keputusan pembelian tanpa mempertimbangkan banyak hal. Dikarenakan sudah seringnya pembelian atas suatu produk tersebut dilakukan.

\section{FAKTOR YANG MEMPENGARUHI KEPUTUSAN PEMBELIAN}

Keputusan Pembelian Konsumen pada ritel dipengaruhi oleh banyak faktor yang bersumber dari internal dan eksternal konsumen. 


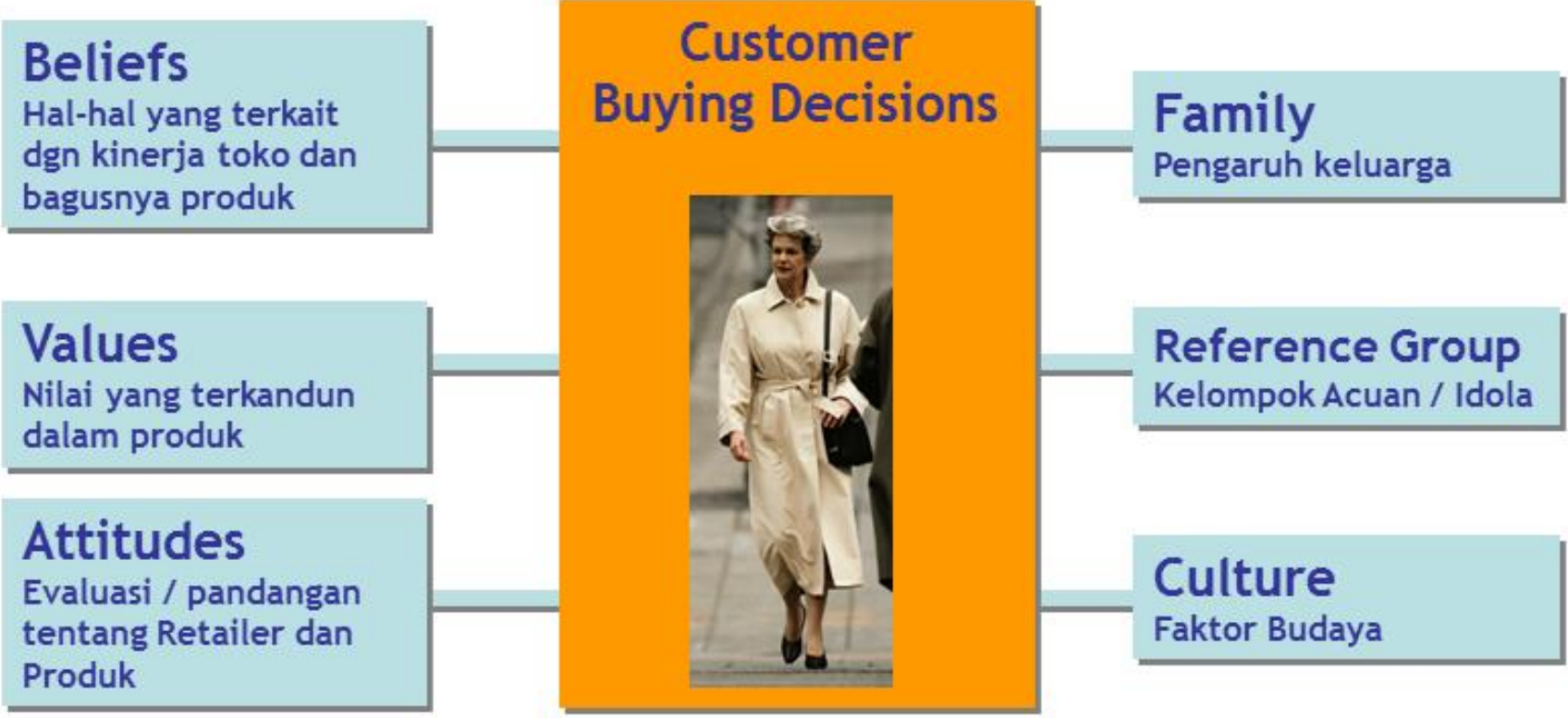

Gambar 5. Faktor-faktor yang Mempengaruhi Keputusan Pembelian Konsumen

Secara Internal, keputusan pembelian konsumen di ritel dipengaruhi oleh Beliefs, Values dan Attitudes yang dianut dan dimiliki konsumen secara personal.

Secara Eksternal, keputusan pembelian konsumen di ritel dipengaruhi oleh Keluarga, Kelompok Acuan dan Faktor Budaya.

Selain itu, terdapat pula konsep psychological needs. Kebutuhan Psikologis, berhubungan dengan kepuasan yang diperoleh konsumen melalui berbelanja (shopping) atau membeli dan memiliki suatu produk termasuk di dalamnya :

1. Stimulation $\sim$ Ritel menggunakan musik, display, demonstrasi dsb sebagai upaya menstimulir konsumen untuk mengunjungi dan melakukan pembelian di ritel. Lalu konsumen menjadikan kunjungannya itu sebagai selingan dari aktivitasnya sehari-hari

2. Social Experiences $\sim$ Ritel memiliki area pusat sosial dimana orang-orang dapat bertemu dengan teman atau membentuk relasi yang baru 
3. Learning New Trends $\sim$ Dengan mengunjungi ritel, orang-orang belajar tentang trend dan ide baru. Kunjungan semacam ini dapat memberi kepuasan kebutuhan konsumen akan informasi tentang lingkungannya

4. Status and Power $\sim$ Konsumen memiliki kebutuhan akan status dan kekuatan yang dapat dipuaskan melalui berbelanja. Untuk beberapa orang, ritel adalah salah satu tempat yang dapat memberikan suatu perhatian dan rasa hormat Ketika berbelanja, mereka bisa menunggu tanpa harus membayar layanan yang diberikan.

5. Self Reward $\sim$ Pelanggan yang sering melakukan pembelian suatu produk sebenarnya telah menghargai dirinya sendiri dengan memenuhi kebutuhannya dan kadang untuk mengusir stres. 


\title{
LEMBAR KERJA
}

1. Sebutkan produk yang di saat memutuskan untuk membelinya menggunakan metode pengambilan keputusan Extended Problem Solving

\author{
Nama Produk:
}

Penjelasan:

2. Sebutkan produk yang di saat memutuskan untuk membelinya menggunakan metode pengambilan keputusan Limited Problem Solving

Nama Produk:

Penjelasan: 
3. Sebutkan produk yang di saat memutuskan untuk membelinya menggunakan metode pengambilan keputusan Habitual Decision Making :

Nama Produk:

Penjelasan:

4. Sebutkan hal yang mempengaruhi keputusan pembelian konsumen, berdasarkan faktor BELIEFS:

Penjelasan: 
5. Sebutkan hal yang mempengaruhi keputusan pembelian konsumen, berdasarkan faktor VALUES:

Penjelasan:

6. Sebutkan hal yang mempengaruhi keputusan pembelian konsumen, berdasarkan faktor ATTITUDES:

Penjelasan: 
7. Sebutkan hal yang mempengaruhi keputusan pembelian konsumen, berdasarkan faktor FAMILY:

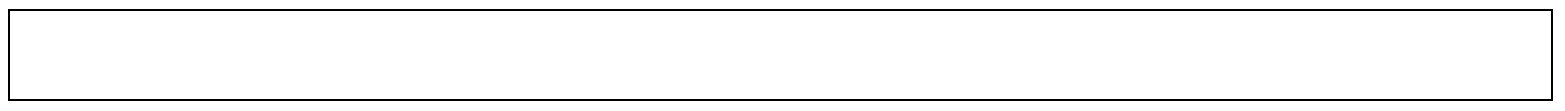

Penjelasan:

8. Sebutkan hal yang mempengaruhi keputusan pembelian konsumen, berdasarkan faktor REFRENCE GROUPS:

Penjelasan: 
9. Sebutkan hal yang mempengaruhi keputusan pembelian konsumen, berdasarkan faktor CULTURE:

Penjelasan: 
14 


\section{DAFTAR REFERENSI}

Anderson, E.; Day, S. G.; Rangan, V.K.., 1997. Strategic Channel Design. Journal of Sloan Management Review, 59-69.

Beaman, Jill A. and Aaron J. Johnson, 2006. A Guide for Manufacturers Food Distribution Channel Overview. EM 8921 • December 2006, the Food Innovation Center, Oregon State University.

Bustiner Irving, 1986. Basic Retailing, Irwin-Homewood, Illinois

Cadilhon, Jean-Josep et. al, 2003. Wholesale Markets and Food Distribution in Europe: New Strategies for Old Functions, Muazhong Agricultural University, China

Carpenter, M.A; Sanders, G, 2007. Strategic Management: a dynamic perspective: concepts and concepts. New Jearsey: Pearson Education.

Dion, Jim. Topping, tap., 1998. Start and Run a Profitable Retail Business, Self Counsel Press, USACanadA.

Golden, Lawrence, W. Zimmerman, Donald A., 1986. Effective Retailing, Second Edition, Houghton Miflin Company, Boston

Joanna Nowakowska-Grunt, 2009. Strategy of Distribution in Food Industry Companies. Annales Universitatis Apulensis Series Oeconomica, 11(2), 2009. Warsawa : Czestochowa University of Technology

Michelle Christian and Gary Gereffi, 2010. The Marketing and Distibution of Fast Food. Springer Science + Business Media.

Petljak, Kristina, 2013. Distribution Channels Of Organic Food In The Republic Of Croatia. POSLOVNA IZVRSNOST ZAGREB, GOD. VII (2013) BR. 1, Croatia.

Pratt Center for Community Development, 2013. Distribution Challenges \& Opportunities for NYC's Small, Specialty Food \& Beverage Manufacturers, August 2013 Report for Food Study.

Turban, E; Leidner, D; McLean, E; Wetherbe, J., 2007. Information Technology for Management. Asia : John Wiley \& Sons, Inc

Pauziah, P. and Mulyana, M., 2018. Formulation of The Green Marketing Development Strategy for the Body Shop Botani Square Bogor. In THE INTERNATIONAL CONFERENCE ON ACCOUNTING AND MANAGEMENT SCIENCE (p. 171).

Hidayat, L., Mulyana, M. and Effendy, M., 2018. Membangun Kepuasan Mahasiswa Pengguna Laboratorium Komputer. JAS-PT Jurnal Analisis Sistem Pendidikan Tinggi, 1(2), pp.93-101.

Sulistiono, S., Nurendah, Y. and Mulyana, M., 2019. Mengukur Minat Studi Siswa SMA dan SMK di Kota Bogor Pada Program Studi Kewirausahaan. JAS-PT Jurnal Analisis Sistem Pendidikan Tinggi, 3(1), pp.112.

Mulyana, M. and Khrisnayoga, P.P., 2019. OBSERVASI PERILAKU KONSUMEN DALAM BERBELANJA ONLINE. 
Nurendah, Y., Mulyana, M. and Muanas, M., 2018. Evaluasi dan Pemetaan Minat Studi Siswa SMA dan SMK di Kota Bogor Pada Program Studi Ekonomi Syariah. JAS-PT Jurnal Analisis Sistem Pendidikan Tinggi, 2(2), pp.83-94.

Nurendah, Y., 2015. Strategy to Improvement Sustainability of Distinctively Local Snacks Based on Evaluation and Profile Mapping of SMEs Distinctively Local Snacks. International Journal on Advanced Science, Engineering and Information Technology, 5(5), pp.334-338.

Binangkitsari, L. and Sulistiono, S., 2018. The Influence of Brand Equity Elements on Purchase Decision and Its Imlication on Customer Loyalty. In THE INTERNATIONAL CONFERENCE ON ACCOUNTING AND MANAGEMENT SCIENCE (p. 305).

H V Purba, J. (2019). The Influence of China's Vegetable Oil Consumption on Indonesia's CPO Exports and Its Implications on IndonesiaChina Trade Balance. Proceeding Interuniversity Forum for Strengthening Academic Competency, 1(1), 203.

Nugroho, J. and Purba, J.H.V., 2018. Analysis of Long-Term Financial Management Policy Case Study PT Sierad Produce Tbk. In THE INTERNATIONAL CONFERENCE ON ACCOUNTING AND MANAGEMENT SCIENCE (p. 323).

Munawar, A., 2018. Analysis Differences Financials Performances on Jokowi Regime. In THE INTERNATIONAL CONFERENCE ON ACCOUNTING AND MANAGEMENT SCIENCE 2018 (p. 96).

Paramita, D. A., \& Fadillah, A. (2019, July 23). Factors That Influence Small Business Performance in OneWay Traffic System Area. Retrieved from osf.io/preprints/inarxiv/kps5c

K., \& Fadillah, A. (2019, July 23). Influence of Celebrity Endorser, Attractiveness and Packaging Impressions on Interest in Watching Pesbukers ANTV. Retrieved from osf.io/preprints/inarxiv/gf4yq 
Ritel telah menjadi bagian tak terpisahkan dari Saluran Distribusi produk dari manufaktur ke konsumen,

Perkembangan bentuk, format dan strategi ritel sudah sedemikian ragam.

Perkembangan tersebut membuka peluang sangat besar bagi SDM yang minat berkarir di bidang ritel.

Buku ini memberi gambaran praktis tentang mengelola bisnis ritel serta pengembangannya

ISBN 978-979-18532-9-0

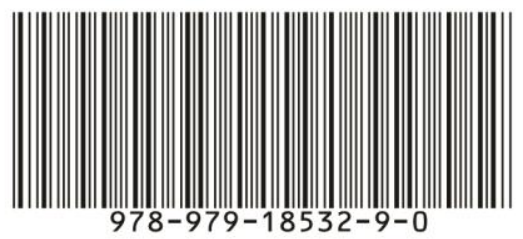

